\title{
Gender Roles and Women Participation in Bee Keeping: A Focus on Baringo South Sub-County, Baringo County
}

\author{
Yator Caroline Jemase, Lilian Chesikaw \\ Institute of Women Gender and Development Studies, Egerton University, Egerton, Kenya
}

Email address:

carojemase@gmail.com (Y. C. Jemase), chesikaw@yahoo.com (L. Chesikaw)

\section{To cite this article:}

Yator Caroline Jemase, Lilian Chesikaw. Gender Roles and Women Participation in Bee Keeping: A Focus on Baringo South Sub-County, Baringo County. Advances in Sciences and Humanities. Vol. 7, No. 2, 2021, pp. 32-37. doi: 10.11648/j.ash.20210702.14

Received: April 6, 2021; Accepted: May 20, 2021; Published: May 31, 2021

\begin{abstract}
This study acknowledges that women participation in bee keeping is still low despite the initiatives and programs by the government and non-governmental organizations to have women participate in bee keeping in Baringo South Sub- County. The study identified that one of the factors blamed in low participation of women in bee farming in most developing countries is gender roles. This is particularly evident in male dominated societies. The study therefore sought to determine the influence of gender roles on women participation in Bee Keeping in Baringo South Sub- County. The study collected data from 128 women sampled from women engaged in bee farming in the sub-county. Data was collected through research questionnaires with closed ended questions that were self-administer by the researcher. The study revealed that gender roles had a significant influence on women participation in beekeeping. Women had huge gender roles that hampered their participation in beekeeping. The study also revealed that the high burden of gender roles on women presented itself in forms such as childrearing, household chores, income generating activities, provision of labour (paid and unpaid) and community development roles, influence female participation in bee keeping. The study recommends that gender roles should not be assigned according to biological and cultural stereotyping in order to create time for women to participate in bee keeping. Greater load with gender roles reduces women participation in beekeeping. Promotion of time saving technologies for household chores could go a long way in creating the much needed time necessary for women participation in beekeeping.
\end{abstract}

Keywords: Gender Roles, Women Participation, Bee Keeping, Baringo South Sub-County

\section{Introduction}

An overview of women involvement and gender roles in beekeeping Previous studies have shown that beekeeping has often been considered a male-dominated enterprise in Uganda, Kenya and Zambia [10, 17]. Further research indicates that women are increasingly taking up beekeeping as an income generating activity in Nyando and Mwingi, Kenya [6, 15]. However, they often encounter social and cultural constraints that hinder them from performing apiary cultural practices [18].

In Africa, beekeeping is a male dominated field. This is evident in countries such as Uganda, Kenya and Zambia [17]. Men reserve the right of making most decisions at the household and the community level in most African countries. Women therefore have less ownership over assets and decision making thus resulting to them not making decisions on issues of beekeeping [15]. Women thus encounter many obstacles as they try to practice bee farming in most African countries. These obstacles include cultural norms and belief that prevent them from setting apiaries or owning hives. Other obstacles include inadequate knowledge on beekeeping, bee-sting phobia as well as the multiple roles they have to play in their households [14].

In Kenya, beekeeping is not an attractive option for women because of cultural issues, inadequate skills on beekeeping, gender stereotypes as well as the multiple roles that take much of their time leaving no time for them to practice beekeeping [1]. Cultural beliefs, norms and stereotypes discourage women from taking this profitable enterprise. For instance, according to many cultures, women will die if they own hives, hoist them, construct or destroy them or will make all bees abscond if they count the number of hives in the farms. Because women are the gate-keepers of 
culture, they believe in that and leave the farming practice for men [15].

In Baringo County, bee keeping is a men's role. Women are not allowed to own or even count the number of bee hives Cultural practices as well as social constraints have hindered them from practicing bee keeping [1]. These constraints include time constraint, inability to climb up trees and harvest honey from traditional log hives as well as the nature of bees kept in the area. African bee, Apis Millifera is very aggressive and women because of bee phobia, get discouraged [3, 14]. Other constraints include the fact that honey harvesting is carried out mostly at night when women are mostly carrying out household chores [15]. Some women in Kipsogon area have broken this barrier and are trying to demystify the norms that bar them from practicing apiculture. Other women still believe in the cultural norms and that is why they are not practicing it. This is despite the campaigns by government and non-governmental organizations aimed at encouraging the women to take part in bee farming. This study focused on the gender roles and their influence on bee farming in Baringo South Sub-County.

Interest in modernizing indigenous agriculture is growing, especially in Africa. Consequently, there is increased pressure that agriculture is not just left as men's affair. According to [20], beekeeping was a male's role in almost all parts of the world. Men were more active in the setting of apiaries, construction of bee hives, honey harvesting and general bee management. Women came in during marketing. This is because many women had a bee phobia and were afraid of the bee sting. Women also lacked time to practice beekeeping because they had other household chores which made them leave the practice for men [11]. Governments from different countries have been trying to address this issue of women not involving themselves in agriculture. In various parts of Africa, beekeeping has been identified as a green area for contemporary agriculture. Bee keeping is becoming very attractive, especially due to the fact that it is not very labor intensive, does not require large tracks of land, and can be practices alongside other agricultural activities. In Kenya, where there have been campaigns from government and nongovernmental institutions, encouraging women, especially those living in arid and semi-arid locations to practice bee farming, empirical evidence indicates that bee farming is still popular among the men. Women are still few in the field. While empirical studies have identified gender roles as some of the determinants of women participation in bee farming, literature gap still exists on the specific gender roles relevant in the context of rural and semi-arid locations, especially in Kenya. This study therefore sought to investigate the gender roles and their influence in beekeeping in Baringo South Sub-County.

\section{Literature Review}

Gender roles determine how activities are divided in bee farming sector [20]. For instance, women are given roles like cleaning the apiary, watering the bees especially during dry seasons, honey processing and honey marketing [11]. Men on the other hand play roles like constructing hives, repairing them when they spoil, hanging the hives on top of trees as well as harvesting honey [12].

Gender roles along the beekeeping practice vary from one country to another. This is because different countries have different cultural practices and beliefs which influence directly or indirectly on roles assigned to men and women practicing beekeeping. In Pakistan, women took part in feeding the bees with supplements, extracting of honey from the combs and packing the honey. Men replaced bee colonies, bred the queens, harvested the honey and marketed it. In Angola for instance, honey harvesting was largely done by men [2]. In Zambia, women were more involved in the processing stage. They convert honey into local beer. Men on the other hand took part in harvesting of the honey, keeping records and took records during group meetings [17].

In Zambia, women were more involved at the honey processing stage of the value chain where they converted harvested honey to a local beer called 'mbote' while men harvested honey, kept records and took minutes during group meetings [17]. At the Kenyan coast, the role of women in beekeeping was cleaning the apiary, watering bees and transporting of hives to the apiary while men offered security, repaired the hives, harvested and marketed honey [12]. Pakistan, involvement of women in beekeeping as an income generating activity has been due to involvement of development agencies through trainings that boost their skills in the management of apiculture [14]. Some of the apiary activities carried out by women in Pakistan include feeding bees with supplements, extraction of honey from combs and packaging. Men on the other hand, replaced bee colonies, breed queens, harvested and marketed processed honey [7].

In Kenya, beekeeping is practiced majorly in areas such as the Coastal region, Kitui County, Mwingi, and Baringo County. Bee keeping has been practiced traditionally for many years. Only twenty percent of the country's honey has been tapped. Eighty percent of the honey comes from the ASAL areas although non-ASAL areas also practice apiculture [12]. ASAL areas is high in honey production because of the abundance in bee flora. At the Kenyan Coast, women clean apiary, water the bees and transported the hives to the apiary. Men offer security, repaired the hives, harvested and marketed the processed honey. Men carry out most of the work and women are assigned roles that go hand in hand with their gender roles. Most of the time, women interact with honey and other hive products during value addition process [17]. This raises a question as to why it is not the initial processes like siting of apiaries and hive hoisting.

Gender roles are socially constructed roles, behaviours, activities and attributes that a given society considers appropriate for men and women [17]. These roles are culturally specific. Traditionally, men and women had opposing roles. Men were seen as providers for the family and women were seen as caretakers of families and homes [5]. Families are constructed around relationships that 
involve responsibilities as well as status and power. Masculinity and femininity are constructed to generate rigid and narrow gender roles [18]. Gender roles determine the responsibilities and tasks assigned to men and women in beekeeping. In the study area, women and men played different roles in beekeeping and these roles were strictly followed as it was considered a taboo for women to play men's roles and vice versa.

In beekeeping, men and women were expected to play different roles since culture has made people to believe so. The roles that women were being assigned included cleaning of apiary, watering of the bees especially during dry seasons when water was scarce and honey processing which involved the extraction of honey from combs. Men on the other hand constructed bee hives, repaired them when they got spoiled, hung the hives, harvested the honey and in some cases sold the honey [12]. This was the case in the study area. Women do not take part in beekeeping because of lack of skills on bee farming, cultural constrains, prohibition by culture from climbing up trees among other [3].

According to [17], women do not take part in beekeeping because of lack of skills on bee farming, cultural constrains, prohibition by culture from climbing up trees among others. According to [7], some women have not yet adopted new technologies well and are still using the traditional methods of beekeeping. The use of traditional methods results to production of little honey which lowers production.

Study by [8] noted that gender roles as a major factor that influences participation in beekeeping. Women have the roles of production, reproduction and that of community development. These roles are usually time consuming, tiresome and repetitive. These roles take much of the women's time leaving no time for other activities like beekeeping. Women with younger children rarely take part in beekeeping because the nurturing role takes most of their time. The findings of this research concur with what Moser and Moser said the multiple roles of women took most of their time since they were many, time consuming and repetitive in nature.

Study by [1] found that gender roles pose a negative influence on bee keeping. Because of the many roles women have, they cannot get time to attend trainings that will enable them learn more on improved technologies. They find it hard to attend social gatherings where in most cases act as platforms for passing information in the society.

\section{Research Methodology}

This study adopted a survey research design. According to [4], a survey research provides the researcher on information with emotions, knowledge, opinions as well as attitudes that the population under study has. The researcher chose Baring Sub County because of existence of a conducive environment for bee keeping and the existence of gender inequalities. The study targeted the 700 women estimated to be in bee beekeeping business in Baringo South Sub-County as the target population. The population was grouped in strata and sampled through stratified random sampling as presented in table 1 below. A sample of 300 women was involved in the study.

Data was collected using structured questionnaires with closed ended questions to collect data on items that could be collected through questionnaires. The questionnaires were administered by the researcher. The researcher used interviews for questions that could not be answered through questionnaires. Before actual data collection, the data collection tools were pretested to ensure validity and reliability requirements are achieved. Validity analysis was done through seeking of expert opinions while reliability test was done through calculation of reliability coefficient. Value greater than 0.7 were obtained indicating that the research instruments were reliable. Ordered Logit Model was used with assumption that females with heavy gender roles were less likely to participate in beekeeping as compared to male as a result of the burden of domestic and household chores unlike male.

\section{Discussions and Conclusions}

The study findings revealed that bee farming among women was low rise with distribution of number of hives among women as shown in table 1.

Table 1. Number of hives owned by the respondents.

\begin{tabular}{lll}
\hline Number of hives & Frequency & Percent \\
\hline $1-10$ & 86 & 67.2 \\
$11-20$ & 26 & 20.3 \\
$21-30$ & 8 & 6.3 \\
$31-40$ & 3 & 2.3 \\
$41-50$ & 4 & 3.1 \\
$51-$ above & 1 & .8 \\
Total & 128 & 100.0 \\
\hline
\end{tabular}

This can be attributed to lack of capital and few flowering plants due to the ASAL nature of the study area. Majority of the respondent had a few bee hives because the hives were not readily available in the area. The people who constructed the log hives which were widely used in the area were few.

Respondents were asked to comment on how gender roles constrain them in their day to day activities as far as beekeeping was concerned. The results are shown in Table 2. 
Table 2. Opinions on gender roles affecting beekeeping.

\begin{tabular}{lllllllll}
\hline Gender roles & SA & A & U & D & SD & Total & Mean & Stdev \\
\hline Childrearing & $31(24.2)$ & $66(51.6)$ & $2(1.6)$ & $21(16.4)$ & $8(6.3)$ & $128(100)$ & 3.711 & 1.185 \\
Household chores & $29(22.7)$ & $42(32.8)$ & $5(3.9)$ & $41(32)$ & $11(8.6)$ & $128(100)$ & 3.289 & 1.352 \\
Income generating activities & $19(14.8)$ & $41(32)$ & $6(4.7)$ & $52(40.6)$ & $10(7.8)$ & $128(100)$ & 3.055 & 1.282 \\
Provision of paid labour & $16(12.5)$ & $35(27.3)$ & $9(7)$ & $60(46.9)$ & $8(6.3)$ & $128(100)$ & 2.930 & 1.224 \\
Provision of unpaid labour & $12(9.4)$ & $40(31.3)$ & $11(8.6)$ & $50(39.1)$ & $15(11.7)$ & $128(100)$ & 2.875 & 1.242 \\
Community development roles & $13(10.2)$ & $11(8.6)$ & $6(4.7)$ & $56(43.8)$ & $42(32.8)$ & $128(100)$ & 2.195 & 1.268 \\
\hline
\end{tabular}

Key: SA - Strongly Agree, A - Agreed, U - Undecided, D - Disagree, SD - Strongly Disagree

From the study results, child rearing was perceived as the major constrain affecting women participation in beekeeping with a mean of (3.7). This could be attributed to the burden of bringing up children. Most women found it hard to leave their young children to practice any form of farming. After childbirth, they took care of their infants until they were grown enough to be left with house-helps or other older siblings. A respondent in an interview schedule reported that, "Whenever she got a baby, she postpones beekeeping roles until her baby reached one year of age." this meant that the lady involved had to delegate beekeeping roles every time she got a baby. This affected her production to a large extend. These findings are consistent with the ones of [5] that many women do not attend social gatherings because of too many roles that they have been assigned to them. Culture has assigned many roles to women and [15] in their study found out that women are the gate-keepers of culture. Therefore most women follow what culture dictates to them especially on issues to do with assignment of gender roles and taboos.

Women have multiple roles of production, reproduction and community development roles. The many household chores were time consuming and repetitive. Women thus spent most of their time doing the many gender roles to the extent of leaving beekeeping aside. From an interview schedule, a respondent reported that, "responsibilities in beekeeping have been divided according to gender. For instance, the men have been given roles such as constructing and repairing bee hives, hoisting of the log hives, colony replacement, queen rearing and honey extraction. On the other hand, the women have been assigned roles such as provision of supplement feeds to the bees, pest management, grading and packaging, marketing and bee wax processing." This is thus in agreement with the work of [14] who found out that men in the olden days were assigned the roles like honey harvesting which was carried out at night. They concluded that beekeeping was totally a gender based activity. However, these roles are changing gradually and this study discovered that women in the present days are doing those roles which were assigned to men earlier. These include honey harvesting, hoisting of bee hives (box hives) as well as replacement of colonies. This can be attributed to trainings and capacity-building on beekeeping matters as well as improvement of technologies in the beekeeping sector.

Majority of the respondents $(60 \%)$ in this study disagreed with the statement that income generating activities hindered their day to day activities. Most respondents outlined that income generating activities provided capital that could be used for beekeeping. Moreover, according to a number of women, bee management did not consume a lot of time. Once a bee hive has been hoisted, the number of activities needed to maintain it reduces. Majority of the respondents $(50 \%)$ did not consent to the statement that provision of paid labour constrained them in their day to day activities. Seven percent of the respondents were undecided. Paid labour could provide an extra capital that could be used for bee maintenance. Moreover, beekeeping was not time consuming and couldn't take most of women's time. They could still balance between beekeeping and providing for the paid labour. Majority of the respondents disagreed with the statement that provision of unpaid labour hindered their day to day activities. Studies in the past researchers have found out that beekeeping was not a type of farming that was time consuming and could be carried out along with other roles comfortably. Majority of the respondents disapproved the statement that community development roles constrained them in their day to day activities.

According to [1], women with young children rarely take part in active beekeeping because those children need a lot of attention and care from their mothers. This is in agreement with the finding of this study. The researcher in this research found out that women in Baringo South Sub-County agreed to the same statement. They gave attention and support to their children until they were able to walk and talk which could be around three years of age. Women were noted to adopt different types of strategies in order to cope with the challenges of gender roles. Respondent's adoption of various copying mechanisms is summarized in Table 3.

Table 3. Coping strategies in dealing with the challenge of gender roles.

\begin{tabular}{|c|c|c|c|c|c|c|c|c|}
\hline Coping mechanisms & SA & $\mathbf{A}$ & $\mathbf{U}$ & D & SD & Total & Mean & Stdev \\
\hline Hiring house-helps & $28(21.9)$ & $74(57.8)$ & $3(2.3)$ & $19(14.8)$ & $4(3.1)$ & $128(100)$ & 3.805 & 1.043 \\
\hline Waiting until children grow up & $6(4.7)$ & $37(28.9)$ & $12(9.4)$ & $59(46.1)$ & $14(10.9)$ & $128(100)$ & 2.703 & 1.139 \\
\hline Carrying children to work places & $7(5.5)$ & $43(33.6)$ & $9(7)$ & $48(37.5)$ & $21(16.4)$ & $128(100)$ & 2.742 & 1.238 \\
\hline Leaving children with husbands & $3(2.3)$ & $24(18.8)$ & $8(6.3)$ & $61(47.7)$ & $32(25)$ & $128(100)$ & 2.258 & 1.103 \\
\hline Leaving children with relatives & $11(8.6)$ & $39(30.5)$ & $15(11.7)$ & $44(34.4)$ & $19(14.8)$ & $128(100)$ & 2.836 & 1.254 \\
\hline
\end{tabular}

Key: SA - Strongly Agree, A - Agreed, U - Undecided, D - Disagree, SD - Strongly Disagree 
From the study results, hiring of house-helps was the most popular strategy of dealing with the burden of gender roles with a mean of (3.8). This could be attributed to the relative advantage of venturing in beekeeping. The extra income generated was able to hire a labourer to assist in the domestic chores. The second major popular strategy was staying at home until children matured in order to venture into beekeeping activities as a full-time employment. Most respondents in the interview schedule reported that, "most of the female beekeepers in trying to balance the reproductive and productive roles have opted to hire house-helps to ease their work and also to ensure the safety of their children. Most women sell their honey in the evening when people are returning from jobs and that means that they will stay until nine at night. Children are supposed to be fed before sunset that implies that the women are supposed to leave their honey selling and go home. To solve this challenge, most women have employed house-helps to partly assist them carry out the nurturing roles. Most of the respondents with a mean of (2.7) disagreed to the statement that waiting until children grew up was a coping mechanism on challenges against gender roles. Women are excellent on multi-tasking and can do their gender roles together with beekeeping.

Most respondents disagreed with a mean of (2.7) to the statement that carrying children to work places was a coping mechanism on challenges against gender roles. Children could not be taken to the work places because handling bees was a dangerous activity and could kill the children. Bee sting is poisonous and can easily kill. Bees tend to follow the smell of honey and since the women handled the honey during processing and packaging, they avoided taking children to their working places since the bees could access the area and cause harm to them. In an interview schedule, a respondent reported that, "she could not take her baby to the selling area since it is cold in the evenings and the infant can easily contract pneumonia. She also needed to run to the customers when vehicles stopped and carrying a baby on the back was an additional cumbersome work." Therefore, most women preferred leaving their children at home with the house-helps or with older children who could take care of them well.

Majority of the respondents with a mean of (2.3) disagreed to the statement that leaving children with husbands was a coping mechanism on challenges against gender roles. An interview schedule reported that, "husbands were not born to take care of children. They don't know how well a baby should be handled. In the bible, a woman was given the role of nurturing and men to provide and not to take care of children. Moreover, I went for circumcision and I was taught that I should never leave my children to be taken cared y my husband." Amongst the Kalenjins, men are not supposed to take care of children and it is purely a women's role. Therefore, women desisted from leaving their young children with their husbands as they carried out bee management.

Majority of the respondents with a mean of (2.8) disagreed to the statement that leaving children with relatives was a coping mechanism on challenges against gender roles. Some relatives could not agree to take care of children because they were busy too with other activities. Women therefore preferred hiring house-helps and pay them instead of leaving the children with relatives.

Objective four was translated into the following research question:

$\mathrm{Qo}_{3}$ : How do gender roles affect women's participation in bee-keeping in Baringo South Sub-County?

The research question was tested using ordered logistic regression. Table 4 shows how gender role influence women's participation in bee-keeping.

Table 4. Ordered logistic regression for the influence of gender roles on women participation in bee-keeping.

\begin{tabular}{|c|c|c|c|c|c|c|}
\hline Extent of women participation in beekeeping & Coef. & Std. Err. & $\mathbf{Z}$ & $\mathbf{P}>\mathbf{Z}$ & \multicolumn{2}{|c|}{ [95\% Conf. Interval] } \\
\hline Gender roles & -0.592 & 0.255 & -2.320 & 0.020 & -1.092 & -0.092 \\
\hline /cut1 & -1.040 & 0.763 & & & -2.536 & 0.457 \\
\hline /cut2 & 0.236 & 0.760 & & & -1.254 & 1.726 \\
\hline /cut3 & 1.030 & 0.784 & & & -0.507 & 2.566 \\
\hline /cut4 & 1.540 & 0.822 & & & -0.071 & 3.152 \\
\hline /cut5 & 3.217 & 1.203 & & & 0.859 & 5.576 \\
\hline
\end{tabular}

$\mathrm{n}=128$; Log likelihood=-125.01; LR chi2 $(1)=5.60$; Prob > chi2=0.018; Pseudo R2=0.264

The log likelihood for the fitted model of -125.01 and the $\log$ likelihood chi-squared value of 5.60 ( $\mathrm{p}$-value $=0.018$ ) indicate that the two parameters in the model are jointly significant at $5 \%$. Pseudo $\mathrm{R}^{2}$ of 0.264 confirms that the extent of women participation in beekeeping was well attributed to gender roles (gender roles account for $26.4 \%$ changes in the extent of women participation in beekeeping). The results in Table 4 show that the coefficient for gender roles $(-0.592)$ was negative and statistically significant at $5 \%$ level (pvalue $=0.020$ ). This implies that greater load with gender roles reduces women participation in beekeeping.

These results are consistent with [5] who found that men and women had opposing roles with men being seen as providers for the family and women being seen as caretakers of families and homes. These roles inevitably disadvantage female from not only their ability to participate in beekeeping, but even in other economic activities. [12] Observed that in beekeeping, men and women play different roles and participate in different extents. This is partly because culture has made them to believe so. The roles that women have been assigned include cleaning of apiary, watering of the bees especially during dry seasons when water is scarce and honey processing which involved the extraction of honey from combs. Men on the other hand constructed bee hives, repaired them 
when they got spoiled, hung the hives, harvested the honey and sold the honey.

Gender roles such as childrearing, household chores, income generating activities, provision of labour (paid and unpaid) and community development roles, influenced female participation in bee keeping. As a result, different coping strategies have emerged in the study area. Such strategies included hiring of house-helps, waiting until children grow up, carrying children to work places as well as, leaving children with husbands and relatives.

Gender roles had a significant influence on women participation in beekeeping. Women had huge gender roles that hampered their participation in beekeeping. The high burden of gender roles on women presented itself in forms such as childrearing, household chores, income generating activities, provision of labour (paid and unpaid) and community development roles, influence female participation in bee keeping

Gender roles should not be assigned according to biological and cultural stereotyping in order to create time for women to participate in bee keeping. Greater load with gender roles reduces women participation in beekeeping. Promotion of time saving technologies for household chores (cleaning, washing, cooking, etc.) could go a long way in creating the much needed time necessary for women participation in beekeeping.

\section{References}

[1] Ahikiriza, E. (2016). Beekeeping as an alternative source of livelihood in Uganda. School of Graduate, Ghent University.

[2] Birhanu, T. A. (2016). Constraints and opportunities of honeybee production and honey marketing systems: a case study of Fuji and Boerne Zone of Oromia State. EC. Agriculture 3 (3): 635-645.

[3] Chemurot, M. (2011). Beekeeping in Adjumani district, Uganda. Bee World, 88 (3), 58-61.

[4] Creswell, J. W., Hanson, W. E., Plano, V. L. C. \& Morales, A. (2007). Qualitative research design: Selection and implementation. Sage journals, 35 (2), 236-264. https://doi.org/10.1177\%2F001100000628739.

[5] Kioko, E. (2010). Agfax: Reporting Science in Africa. Retrieved January 30, 2013, from Agfax: http://www.agfax.net at $1000 \mathrm{hrs}$.

[6] Macoloo, C., Recha, J., Radeny, M., \& Kinyangi, J. (2013). Empowering a local community to address climate risks and food insecurity in Lower Nyando, Kenya. Case study for Hunger, Nutrition and climate justice, a new dialogue; putting people at the heart of global development. Dublin, Ireland, nature publishing.

[7] Mburu, P. D. M. (2015). Mapping of the honey value chain and analysis of changes in gender roles and factors influencing women empowerment among beekeepers in Kitui County, Kenya (Doctoral dissertation). University of Nairobi, Nairobi.
[8] Moser, C. \& Moser, A. (2005). 'Gender mainstreaming since Beijing: A Review of success and limitations in International Institutions'. In Porter, F. \& Sweetman, C. (eds.), Mainstreaming gender in development, a critical review. United Kingdom, Oxford Press.

[9] Mujuni, A., Natukunda, K. \& Kugonza, D. R. (2012). Factors affecting the adoption of beekeeping and associated technologies in Bushenyi District, Western Uganda. Development, 24, 8.

[10] Oduol, J., Place, F., Mithöfer, D., Olwande, J., Kirimi, L., \& Mathenge, M. (2013). Improving participation in agricultural commodity markets for smallholder avocado farmers in Kenya: assessing growth opportunities for women in Kandara and Marani districts. Tegemeo Institute, Egerton University. Retrieved from http://www.tegemeo.org/images/downloads/publications/techn ical_reports/TR4.pdf on, 22 February 2019.

[11] PactKenya. (2010). Scoping study and value chain analysis for bee keeping and honey products. Retrieved from www.PactKenya.org on $31^{\text {st }}$ May 31, 2019 1010hrs.

[12] Qaiser, T., Ali, M., \& Taj, M. (2010). Scoping study and value chain analysis for bee keeping and honey products. Journal of Social Sciences (COES\&RJ-JSS) Vol, 2.

[13] Qaiser, T., Ali, M., Taj, S., \& Akmal, N. (2013). Impact assessment of beekeeping in sustainable rural livelihood. Journal of Social Sciences (COES\&RJ-JSS) Vol, 2.

[14] Raina, S. K., Kioko, E. N., Gordon, I. \& Nyandiga, C. (2009). Improving forest conservation and community livelihoods through income generation from commercial insects in three Kenyan forests. Nairobi, International centre of insect physiology and ecology.

[15] Ross, A. C. (2009). Securing communal land rights to achieve sustainable development in Sub-Saharan Africa: critical analysis and policy implications. Journal of Law. Environment and Development, 5 (2), 130-141.

[16] Shackleton, S., Paumgarten, F., Kassa, H., Husselman, M., \& Zida, M. (2011). Opportunities for enhancing poor women's socioeconomic empowerment in the value chains of three African non-timber forest products (NTFPs). International Forestry Review, doi: 136-151.10.1505/146554811797406642.

[17] Shire, D., Asabi, G. \& Mergers, E. (2016). Identifying Opportunities and Constraints of Beekeeping: A case of Gamblezeria and God ereWeredas. Gamble Regional State, Ethiopia. Entomol Ornitology, Herpotol 5: 182.

[18] Wadji, D. N., Pouomgne, V., Binam, J. N. \& Nouaga R. Y. (2012). Farmers' perceptions and adoption of new Acquaculture Technologies in the Western Highland of Cameroon. Tropiculture. Cameroon University Press.

[19] Weber, E. (2013). Apis mellifera: The domestication of European honey bee for agriculture in North America. England, Oxford Press.

[20] Zwarteveen, M. (2008). Men, masculinities and water powers in irrigation. Water Alternative, 1 (2), 111-113. 